\title{
Effect of two-stage sintering process on microstructure and mechanical properties of ODS tungsten heavy alloy
}

\author{
Kyong H. Lee ${ }^{\text {a }}$, Seung I. Cha ${ }^{\mathrm{b}}$, Ho J. Ryu ${ }^{\mathrm{c}}$, Soon H. Hong ${ }^{\mathrm{a}, *}$ \\ a Department of Materials Science and Engineering, Korea Advanced Institute of Science and Technology, 373-1 Kusong-dong, \\ Yusong-gu, Taejon 305-701, Korea \\ b International Center for Young Scientists, National Institute for Materials Science 1-1, Namiki, Tsukuba 305-0044, Japan \\ ${ }^{\mathrm{c}}$ DUPIC, Korea Atomic Energy Research Institute, 150 Deokjin-dong, Yusong-gu, Taejon 305-353, Korea
}

Received 28 May 2006; received in revised form 12 December 2006; accepted 30 January 2007

\begin{abstract}
Oxide dispersion strengthened (ODS) tungsten heavy alloys have been considered as promising candidates for advanced kinetic energy penetrator due to their characteristic fracture mode compared to conventional tungsten heavy alloy. In order to obtain high relative density, the ODS tungsten heavy alloy needs to be sintered at higher temperature for longer time, however, induces growth of tungsten grains. Therefore, it is very difficult to obtain controlled microstructure of ODS tungsten heavy alloy having fine tungsten grains with full densification. In this study, two-stage sintering process, consisted of primary solid-state sintering and followed by secondary liquid phase sintering, was introduced for ODS tungsten heavy alloys. The mechanically alloyed $94 \mathrm{~W}-4.56 \mathrm{Ni}-1.14 \mathrm{Fe}-0.3 \mathrm{Y}_{2} \mathrm{O}_{3}$ powders are solid-state sintered at $1300-1450{ }^{\circ} \mathrm{C}$ for $1 \mathrm{~h}$ in hydrogen atmosphere, and followed by liquid phase sintering temperature at $1465-1485^{\circ} \mathrm{C}$ for $0-60 \mathrm{~min}$. The microstructure of ODS tungsten heavy alloys showed high relative density above $97 \%$, with contiguous tungsten grains after primary solid-state sintering. The microstructure of solid-state sintered ODS tungsten heavy alloy was changed into spherical tungsten grains embedded in $\mathrm{W}-\mathrm{Ni}-\mathrm{Fe}$ matrix during secondary liquid phase sintering. The twostage sintered ODS tungsten heavy alloy from mechanically alloyed powders showed finer microstructure and higher mechanical properties than conventional liquid phase sintered alloy. The mechanical properties of ODS tungsten heavy alloys are dependent on the microstructural parameters such as tungsten grain size, matrix volume fraction and tungsten/tungsten contiguity, which can be controlled through the two-stage sintering process. (C) 2007 Elsevier B.V. All rights reserved.
\end{abstract}

Keywords: Oxide dispersion strengthened (ODS); Tungsten heavy alloy; Mechanical alloying; Two-stage sintering; Microstructure; Mechanical properties

\section{Introduction}

Tungsten heavy alloys are widely used as kinetic energy penetrators, counter weight balances, radiation shields and vibration damping devices due to their high density, excellent strength and good ductility [1,2]. Several studies have been carried out to enhance the mechanical properties of tungsten heavy alloy in order to improve the penetration performance for kinetic energy penetrator applications [3-7,21]. Recently, many investigators have studied the improvement of the mechanical properties by alloying with refractory elements such as Mo and Re [8,9], cold working followed by recrystallization [10], mechanical alloying $[11-17]$ and oxide dispersion $[16,17]$ in order to improve the mechanical properties.

\footnotetext{
* Corresponding author. Tel.: +82 42869 3327; fax: +82 428693310 . E-mail address: shhong@kaist.ac.kr (S.H. Hong).
}

Oxide dispersion strengthened (ODS) tungsten heavy alloy is one of the most promising candidates for kinetic energy penetrator owing to their high strength at elevated temperature and possibility to control the fracture mode from ductile to brittle fracture according to oxide content [17]. This indicates that the self-sharpening behavior of tungsten heavy alloy could be enhanced by the homogeneous distribution of ultra-fine oxide particles [16,17]. Even though the previous research results have verified the possibility to improve penetration performance of tungsten heavy alloy by addition of ultra-fine oxide particles due to self-sharpening behavior during high speed impact test $[16,17]$, high liquid phase sintering temperature and long sintering time are required to obtain high relative density after sintering, which induces large tungsten grain size over $25 \mu \mathrm{m}$. Therefore, it needs a modification in sintering process to obtain both fine tungsten grain size and high relative density.

In this study, two-stage sintering process, which was introduced for mechanically alloyed tungsten heavy alloy powders 
[15], was introduced for ODS tungsten heavy alloy to control the microstructure and mechanical properties. Primary solidstate sintering was carried out to achieve near full densification of mechanically alloyed ODS tungsten heavy alloy and followed by secondary liquid phase sintering with a rapid heating rate and a short holding time to control the microstructural parameters such as tungsten grain size, tungsten/tungsten contiguity and matrix volume fraction as second stage sintering. At the same time, the effect of microstructural factors on mechanical properties of ODS tungsten heavy alloy was analysed in wide range of microstructural parameters.

\section{Experimental procedures}

Elemental powders of $\mathrm{W}(3 \mu \mathrm{m}), \mathrm{Ni}(6 \mu \mathrm{m}), \mathrm{Fe}(3 \mu \mathrm{m})$ and $\mathrm{Y}_{2} \mathrm{O}_{3}(10 \mu \mathrm{m})$ were prepared based on the designed composition of 94 wt. $\% \mathrm{~W}-4.56 \mathrm{wt} . \% \mathrm{Ni}-1.14 \mathrm{wt} . \% \mathrm{Fe}-0.3 \mathrm{wt} . \% \mathrm{Y}_{2} \mathrm{O}_{3}$. The powders were mechanically alloyed with two-step mechanical alloying process, consisted of primary milling and secondary milling, using a planetary mill supplied by Fritsch $\mathrm{GmbH}$. At a primary milling, tungsten and $\mathrm{Y}_{2} \mathrm{O}_{3}$ particles were mechanically alloyed for $6 \mathrm{~h}$ with a rotation speed of $200 \mathrm{rpm}$ and ball-to-powder ratio of 10:1. Secondary milling was performed with same condition after addition of $\mathrm{Ni}$ and $\mathrm{Fe}$ powder to firstly mechanically alloyed $\mathrm{W}$ and $\mathrm{Y}_{2} \mathrm{O}_{3}$ powder. This two-step mechanical alloying process induces that the $\mathrm{Y}_{2} \mathrm{O}_{3}$ particles are dispersed mainly in tungsten grains after sintering.

The mechanically alloyed powders were consolidated into green compacts by die compaction under a pressure of $200 \mathrm{MPa}$. The green compacts were sintered by two-stage sintering process, consisted of primary solid-state sintering and secondary liquid phase sintering. As a primary sintering, solid-state sintering was performed at various temperatures from 1300 to $1450{ }^{\circ} \mathrm{C}$ for $1 \mathrm{~h}$ in hydrogen atmosphere. Primary solid-state sintered ODS tungsten heavy alloy was subsequently secondary liquid phase sintered at temperatures ranging from 1465 to $1485^{\circ} \mathrm{C}$ for 0-60 min in argon atmosphere by rapidly pushing the sample into the furnace hot zone. Fig. 1 shows a two-stage sintering

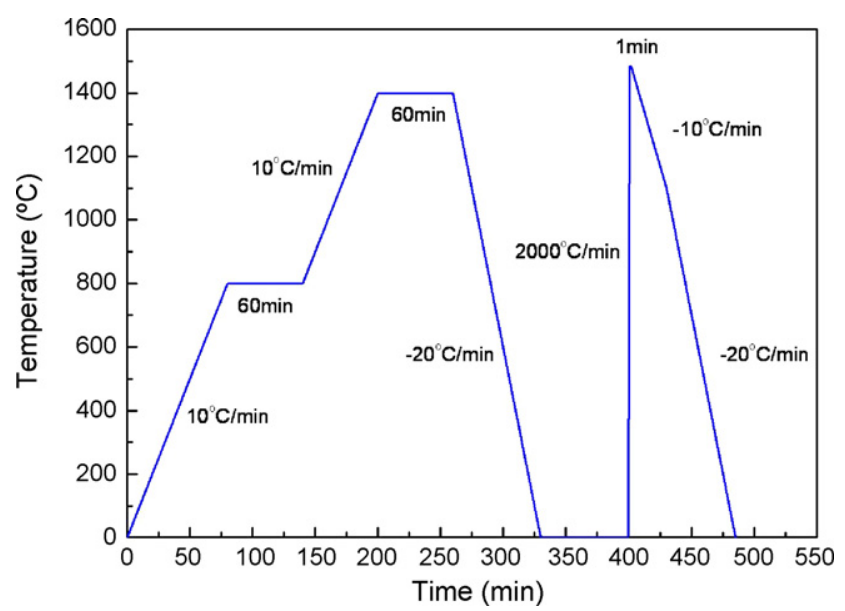

Fig. 1. The sintering temperature profile for a two-stage sintering of ODS tungsten heavy alloys, when the secondary sintering is carried out at $1485^{\circ} \mathrm{C}$ for $1 \mathrm{~min}$. temperature cycle when the secondary sintering temperature is $1485^{\circ} \mathrm{C}$ and the secondary sintering time is $1 \mathrm{~min}$. The twostage sintered specimens were heat-treated at $1150^{\circ} \mathrm{C}$ for $1 \mathrm{~h}$ in nitrogen atmosphere and then water-quenched to prevent hydrogen embrittlement and impurity segregation during the cooling stage [22].

The density of sintered ODS tungsten heavy alloys was measured according to ASTM D792 standard. The mean size of tungsten grains, volume fraction of matrix phase and tungsten/tungsten contiguity of sintered ODS tungsten heavy alloys were characterized using optical and scanning electron microscopy. Mechanical properties of ODS tungsten heavy alloy were characterized by tensile test based on ASTM E$8 \mathrm{M}$. The tensile test was performed under constant strain rate of $6.67 \times 10^{-4} \mathrm{~s}^{-1}$ using Instron 5583 machine. The strain of specimen during the tensile test was measured by an extensometer.

\section{Results and discussion}

\subsection{Microstructural control of oxide dispersion strengthened tungsten heavy alloys by two-stage sintering process}

Fig. 2 shows the microstructure of $94 \mathrm{~W}-4.56 \mathrm{Ni}-$ $1.14 \mathrm{Fe}-0.3 \mathrm{Y}_{2} \mathrm{O}_{3}$ alloys after primary solid-state sintering from two-step mechanically alloyed powder at the temperature ranged from 1300 to $1450{ }^{\circ} \mathrm{C}$ for $1 \mathrm{~h}$. By mechanical alloying of constituent phases, there showed homogeneously distributed matrix without matrix pool. At the same time, the tungsten grains, with finer size than $3 \mu \mathrm{m}$, were interconnected to each other. These results indicate that the two-step mechanical alloying followed by solid-state sintering is very effective to refine the tungsten grain size of ODS tungsten heavy alloys. However, ODS tungsten heavy alloys showed lower relative density from 90 to $97 \%$ after primary solid-state sintering, and they became above $99 \%$ after secondary sintering at the temperature above $1465^{\circ} \mathrm{C}$. In order to obtain both high relative density and fine tungsten grain size, the primary sintering temperature is fixed as $1400{ }^{\circ} \mathrm{C}$ where the relative density is $97 \%$ and the tungsten grain size is $2 \mu \mathrm{m}$, for followed secondary sintering liquid phase sintering process.

The microstructure of $94 \mathrm{~W}-4.56 \mathrm{Ni}-1.14 \mathrm{Fe}-0.3 \mathrm{Y}_{2} \mathrm{O}_{3}$ alloys changed dramatically according to secondary liquid phase sintering temperature when the secondary sintering time is fixed to $30 \mathrm{~min}$ as shown in Fig. 3. Tungsten grains in ODS tungsten heavy alloy, secondarily liquid phase sintered at $1465^{\circ} \mathrm{C}$ for $30 \mathrm{~min}$, remained as highly contiguous shape similar to those solid-state sintered at $1400^{\circ} \mathrm{C}$ for $1 \mathrm{~h}$. However, the shape of tungsten grains became spherical when the secondary sintering temperature is above $1475^{\circ} \mathrm{C}$ and sintering time is $30 \mathrm{~min}$. The tungsten grain size and matrix volume fraction increased, but tungsten/tungsten contiguity decreased with increasing the secondary sintering temperature as shown in Fig. 4.

The effect of secondary sintering time at a temperature of $1485^{\circ} \mathrm{C}$ on microstructure of $94 \mathrm{~W}-4.56 \mathrm{Ni}-1.14 \mathrm{Fe}-0.3 \mathrm{Y}_{2} \mathrm{O}_{3}$ 

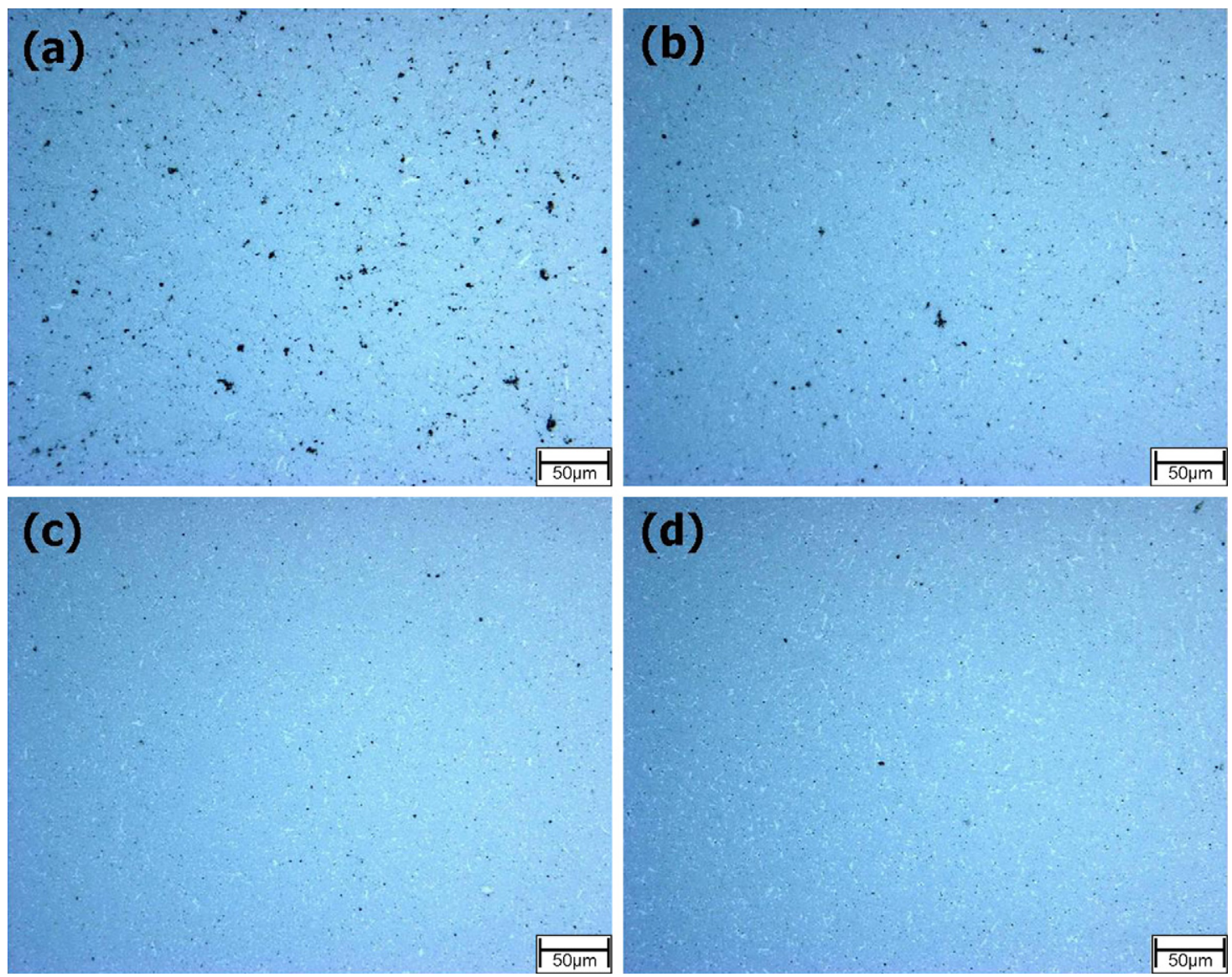

Fig. 2. Microstructure of the solid-state sintered $94 \mathrm{~W}-4.56 \mathrm{Ni}-1.14 \mathrm{Fe}-0.3 \mathrm{Y}_{2} \mathrm{O}_{3}$ tungsten heavy alloy at: (a) $1300{ }^{\circ} \mathrm{C}$, (b) $1350{ }^{\circ} \mathrm{C}$, (c) $1400^{\circ} \mathrm{C}$ and (d) $1450{ }^{\circ} \mathrm{C}$ for $1 \mathrm{~h}$ from two-step mechanically alloyed powder.

alloy is shown in Fig. 5. The average tungsten grain size increased from 1.8 to $19.8 \mu \mathrm{m}$ with increasing secondary sintering time from 0 to $60 \mathrm{~min}$ at $1485^{\circ} \mathrm{C}$ and the tungsten/tungsten contiguity decreased from 0.73 to 0.58 . The relationship between tungsten grain size and secondary sintering time was found to satisfy the LSW theory $[18,19]$ with diffusion control process as followed:

$\bar{r}_{t}^{3}-\bar{r}_{0}^{3}=k\left(t-t_{0}\right)$

where $\bar{r}_{t}$ is the average radius of particles at time, $t, \bar{r}_{0}$ the average radius of particles at time, $t_{0}$, and $k$ is the coarsening rate constant. The coarsening rate constant, $k$, for a mechanically alloyed $94 \mathrm{~W}-4.56 \mathrm{Ni}-1.14 \mathrm{Fe}-0.3 \mathrm{Y}_{2} \mathrm{O}_{3}$ alloy was measured as $16.5 \mu \mathrm{m}^{3} \mathrm{~min}^{-1}$ at $1485^{\circ} \mathrm{C}$, as shown in Fig. 6(b), which is much slower than those of conventional tungsten heavy alloy $\left(25.5 \mu \mathrm{m}^{3} \mathrm{~min}^{-1}\right)$ due to the grain growth inhibition of oxide particles [15,17]. This means that the tungsten grain size of ODS tungsten heavy alloys can be controlled more precisely by the two-stage sintering process compared to conventional tungsten heavy alloy. The two-stage sintered $94 \mathrm{~W}-4.56 \mathrm{Ni}-1.14 \mathrm{Fe}-0.3 \mathrm{Y}_{2} \mathrm{O}_{3}$ tungsten heavy alloy showed finer tungsten grain size of $19.3 \mu \mathrm{m}$ with similar matrix volume fraction and tungsten/tungsten contiguity compared to the conventional liquid phase sintered ODS tungsten heavy alloy.

\subsection{Mechanical properties of tungsten heavy alloys by two-stage sintering process}

The effect of secondary sintering temperature on yield strength and ultimate tensile strength of two-stage sintered $94 \mathrm{~W}-4.56 \mathrm{Ni}-1.14 \mathrm{Fe}-0.3 \mathrm{Y}_{2} \mathrm{O}_{3}$ tungsten heavy alloy is shown in Fig. 7(a). The yield strength of ODS tungsten heavy alloys was sensitive to the sintering temperature ranged from 1465 to $1485^{\circ} \mathrm{C}$. With increasing sintering temperature with a given sintering time of $30 \mathrm{~min}$, the yield strength decreased from 893 to $661 \mathrm{MPa}$, but ultimate tensile strength remained similar level of about $950 \mathrm{MPa}$. The elongation of ODS tungsten heavy alloy increased with increasing the sintering temperature as shown in Fig. 7(b). The elongation of two-stage sintered ODS tungsten heavy alloys increased from 0.5 to $11 \%$ with increasing secondary sintering temperature.

The effect of secondary sintering time on yield and tensile strength of two-stage sintered $94 \mathrm{~W}-4.56 \mathrm{Ni}-1.14 \mathrm{Fe}-0.3 \mathrm{Y}_{2} \mathrm{O}_{3}$ alloy is shown in Fig. 8(a). The yield strength of ODS tungsten heavy alloy decreased from 952 to $639 \mathrm{MPa}$, at the same time, the ultimate tensile strength decreased from 1000 to $883 \mathrm{MPa}$ with increasing the secondary sintering from 5 to $60 \mathrm{~min}$. The elongation of two-stage sintered ODS tungsten heavy alloys increased with increasing the sintering time as shown in Fig. 8(b). In the case of ODS tungsten heavy alloy secondarily sintered at 


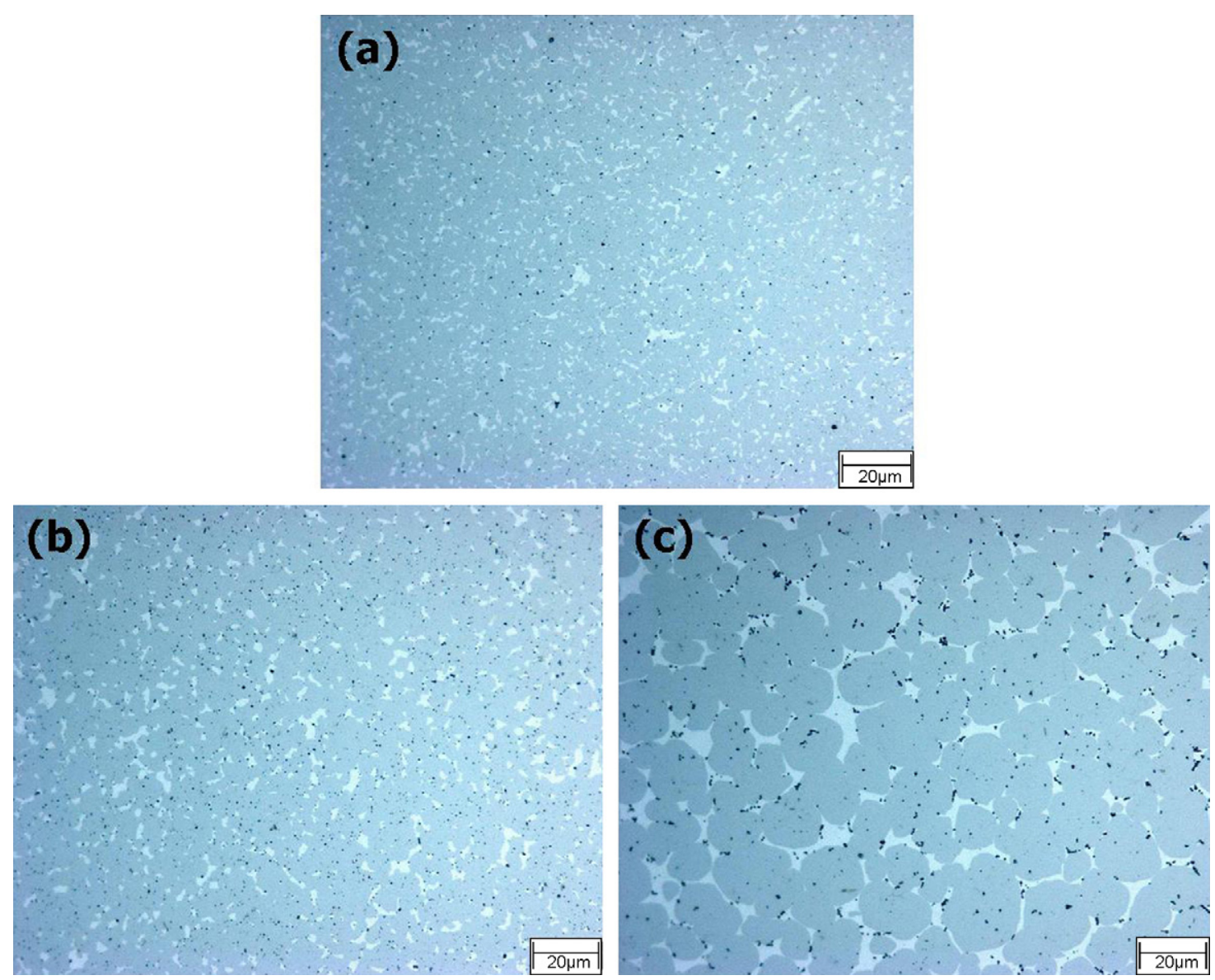

Fig. 3. Microstructure of two-stage sintered $94 \mathrm{~W}-4.56 \mathrm{Ni}-1.14 \mathrm{Fe}-0.3 \mathrm{Y}_{2} \mathrm{O}_{3}$ tungsten heavy alloys liquid phase sintered at: (a) $1465^{\circ} \mathrm{C}$, (b) $1475{ }^{\circ} \mathrm{C}$ and (c) $1485^{\circ} \mathrm{C}$ for $30 \mathrm{~min}$ after solid-state sintering at $1400^{\circ} \mathrm{C}$ for $1 \mathrm{~h}$.

$1485^{\circ} \mathrm{C}$ for $0-3 \mathrm{~min}$, they showed brittle fracture without macroscopic yielding behavior. However, the elongation of ODS tungsten heavy alloy increased to $12.3 \%$ when sintered for $60 \mathrm{~min}$.

Yield strength of tungsten heavy alloy can be formulated using the Hall-Petch relationship of mean matrix thickness under an assumption that the yielding is occurred by deformation of matrix as follows [12,20],

$\sigma_{\mathrm{y}}=\sigma_{0}+k G b \lambda^{-1 / 2}$

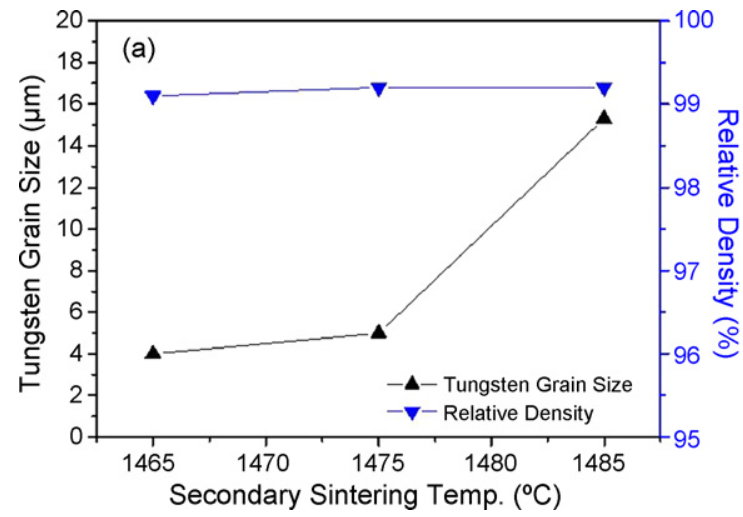

where $\sigma_{\mathrm{y}}$ is yield strength, $\sigma_{0}$ the intrinsic strength, $k$ the constant, $G$ the shear modulus and $b$ the Burgers vector. Matrix thickness can be formulated in terms of tungsten grain size, tungsten/tungsten contiguity, and matrix volume fraction using geometrical relationship as follows,

$\lambda=D \frac{V_{\mathrm{M}}}{C_{\mathrm{W}}\left(1-V_{\mathrm{M}}\right)}$

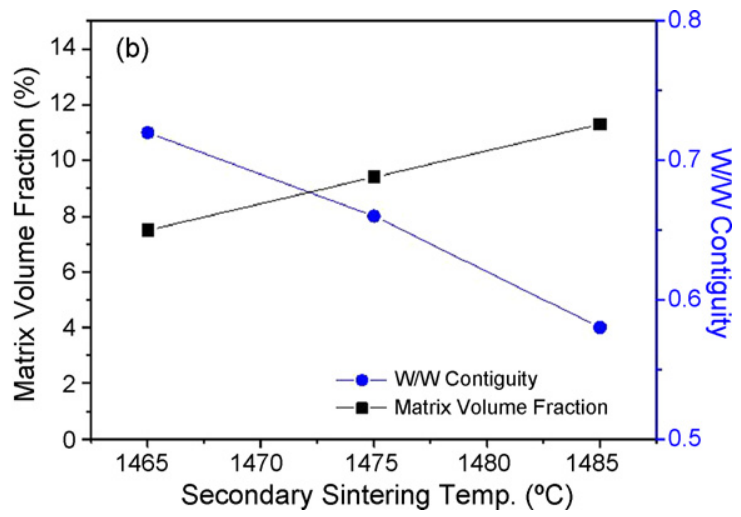

Fig. 4. The variation of: (a) tungsten grain size and relative density and (b) matrix volume fraction and tungsten/tungsten contiguity of two-stage sintered $94 \mathrm{~W}-4.56 \mathrm{Ni}-1.14 \mathrm{Fe}-0.3 \mathrm{Y}_{2} \mathrm{O}_{3}$ tungsten heavy alloys with secondary sintering temperature ranging from 1465 to $1485^{\circ} \mathrm{C}$ with fixed sintering time of 30 min. 


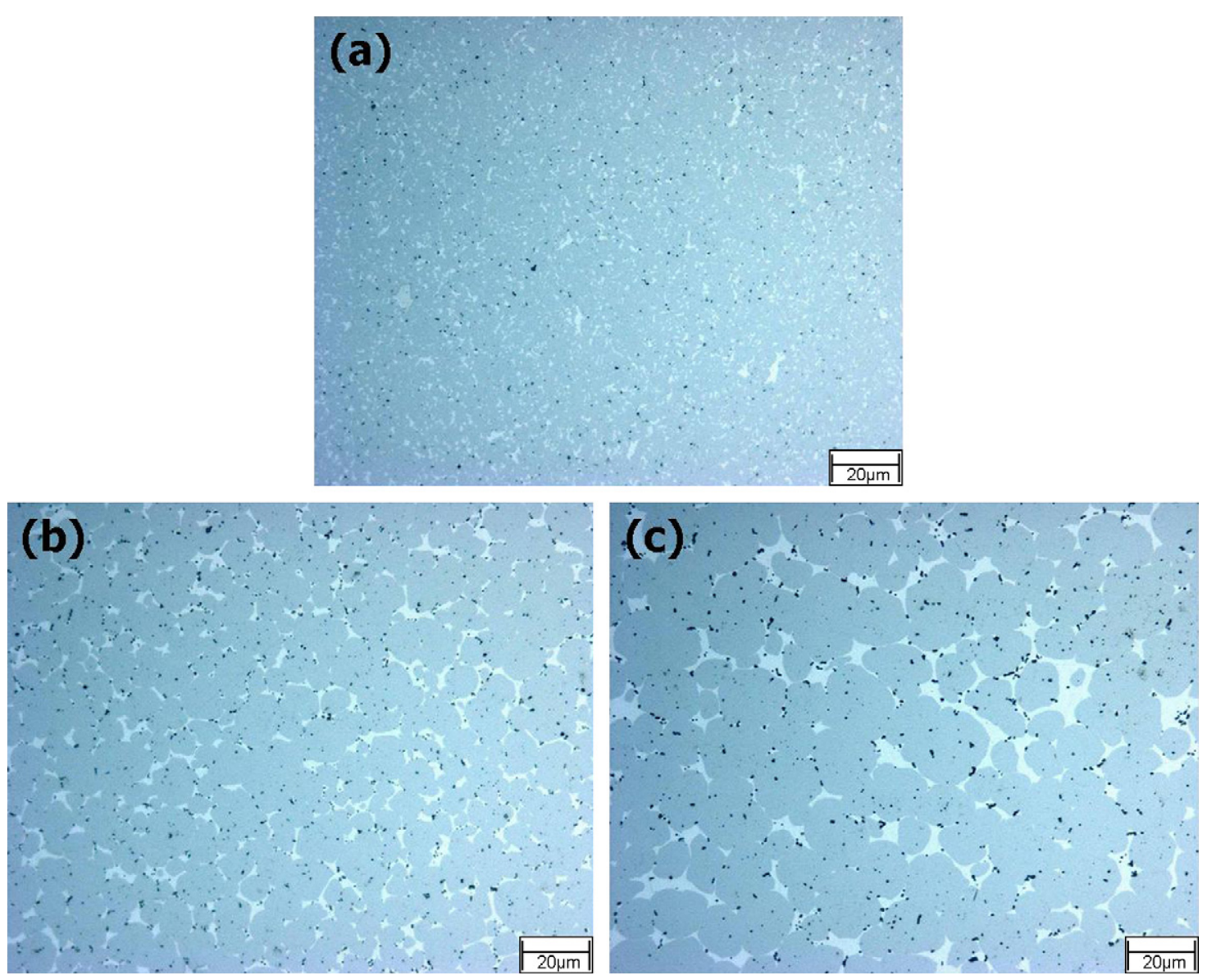

Fig. 5. Microstructure of two-stage sintered $94 \mathrm{~W}-4.56 \mathrm{Ni}-1.14 \mathrm{Fe}-0.3 \mathrm{Y}_{2} \mathrm{O}_{3}$ tungsten heavy alloys secondarily sintered at $1485^{\circ} \mathrm{C}$ for: (a) $0 \mathrm{~min}$, (b) $10 \mathrm{~min}$ and (c) $60 \mathrm{~min}$ after solid-state sintering at $1400^{\circ} \mathrm{C}$ for $1 \mathrm{~h}$.

where $D$ is the mean size of tungsten grains, $C_{\mathrm{W}}$ the tungsten/tungsten contiguity and $V_{\mathrm{M}}$ is the matrix volume fraction. Then the relationship between yield strength and microstructural parameters, i.e. tungsten grain size, tungsten/tungsten contiguity and matrix volume fraction, is expressed as following Eq. (4),

$\sigma_{\mathrm{y}}=\sigma_{0}+k_{2} G b\left(\frac{C_{\mathrm{W}}\left(1-V_{\mathrm{M}}\right)}{D V_{\mathrm{M}}}\right)^{1 / 2}$

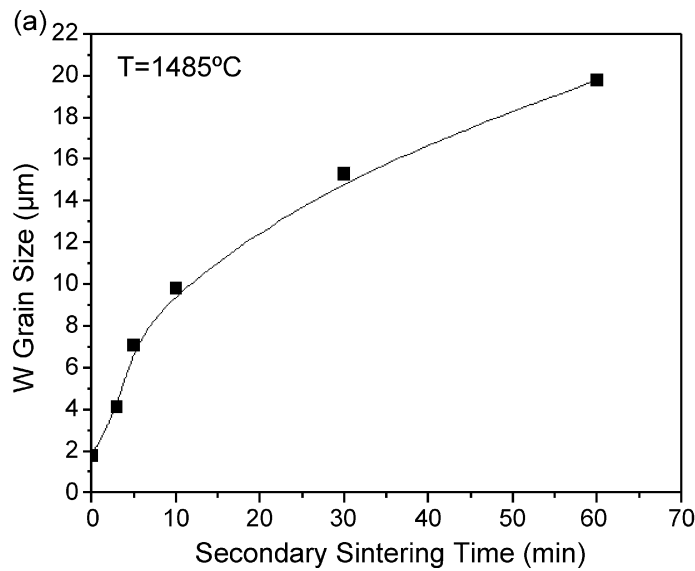

According to Eq. (4), yield strength of ODS tungsten heavy alloys increases with decreasing the tungsten grain size and matrix volume fraction. Fig. 9 shows that the yield strength of ODS tungsten heavy alloys after sintered under with several conditions including solid-state sintering, liquid phase sintering and two-stage sintering, which have a wide range of microstructural parameters such as tungsten grain size, matrix volume fraction and tungsten/tungsten con-

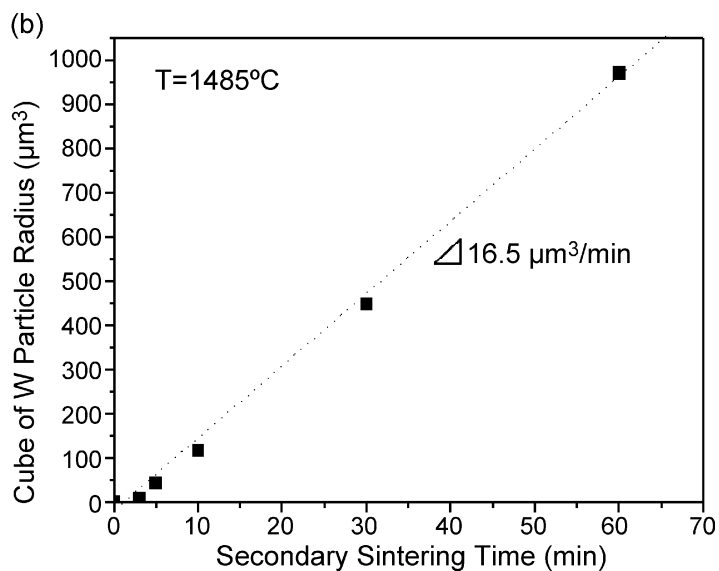

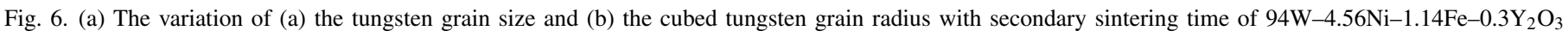
tungsten heavy alloys, when the secondary sintering temperature was $1485^{\circ} \mathrm{C}$. 

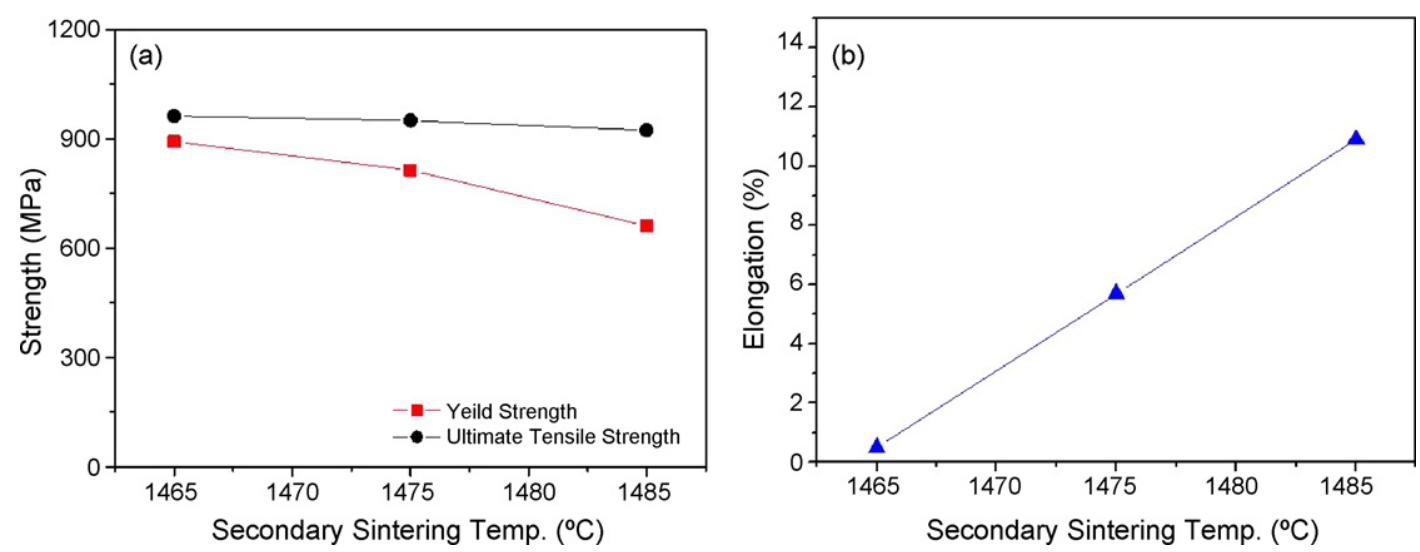

Fig. 7. (a) Tensile strength and (b) elongation of two-stage sintered $94 \mathrm{~W}-4.56 \mathrm{Ni}-1.14 \mathrm{Fe}-0.3 \mathrm{Y}_{2} \mathrm{O}_{3}$ tungsten heavy alloys with varying the secondary sintering temperature for a given sintering time of $30 \mathrm{~min}$.
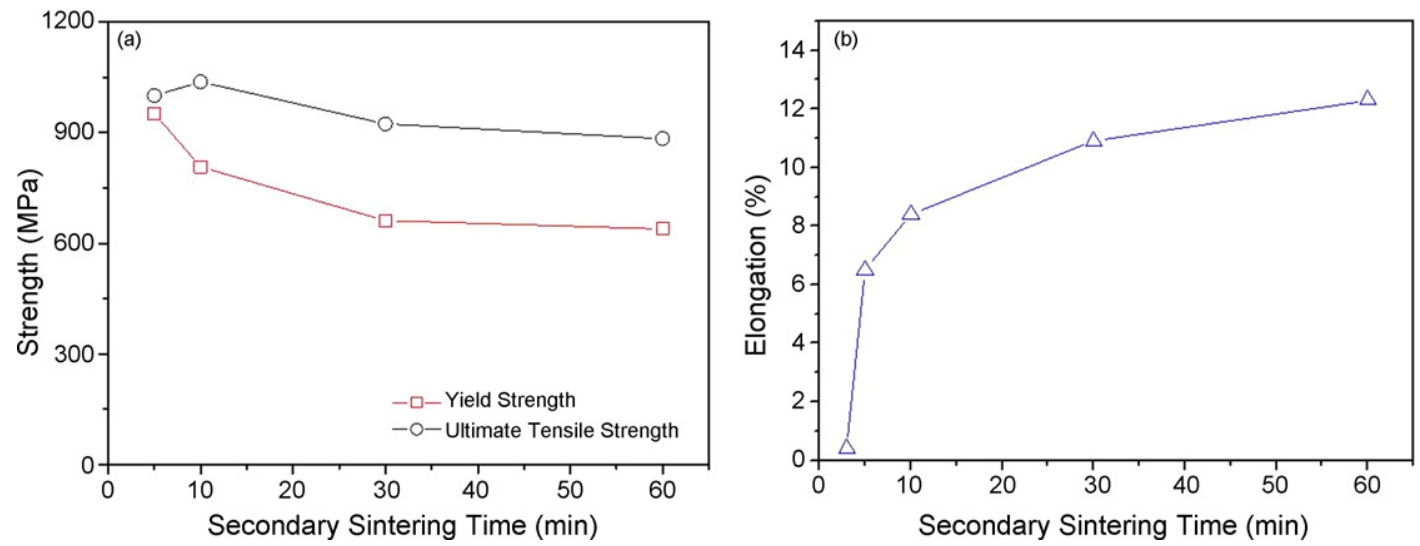

Fig. 8. (a) Tensile strength and (b) elongation of two-stage sintered $94 \mathrm{~W}-4.56 \mathrm{Ni}-1.14 \mathrm{Fe}-0.3 \mathrm{Y}_{2} \mathrm{O}_{3}$ tungsten heavy alloys with varying secondary sintering time at a given sintering temperature of $1485^{\circ} \mathrm{C}$.

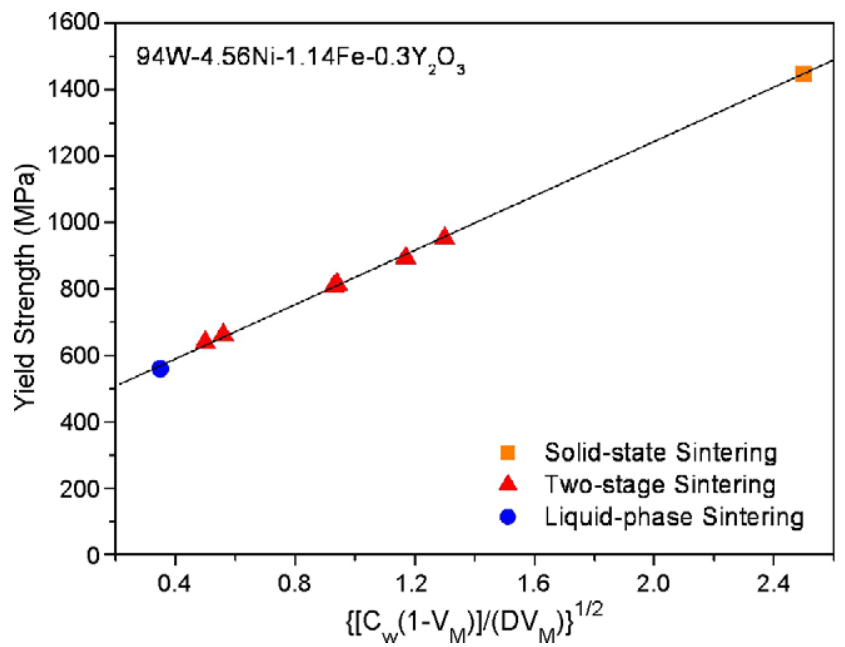

Fig. 9. Variation of yield strength as a function of microstructural parameters including the matrix volume fraction, $V_{\mathrm{M}}$, tungsten/tungsten contiguity, $C_{\mathrm{W}}$, and tungsten grain size, $D$, of solid-state sintered, two-stage sintered and liquid phase sintered $94 \mathrm{~W}-4.56 \mathrm{Ni}-1.14 \mathrm{Fe}-0.3 \mathrm{Y}_{2} \mathrm{O}_{3}$ tungsten heavy alloys.

tiguity, agreed well with Eq. (4). Therefore, it is concluded that the main strengthening effect of ODS tungsten heavy alloys is caused by deformation of matrix at room temperature.

\section{Conclusions}

The microstructure and mechanical properties of ODS tungsten heavy alloys were investigated. The ODS tungsten heavy alloys were fabricated by mechanical alloying process followed by two-stage sintering process. The major results are summarized as follows:

(1) ODS tungsten heavy alloy showed ultra-fine tungsten grain size of $2 \mu \mathrm{m}$ with relative density above $97 \%$ when solidstate sintered at $1400{ }^{\circ} \mathrm{C}$ for $1 \mathrm{~h}$. Solid-state sintered ODS tungsten heavy alloy exhibited high tensile strength about $1450 \mathrm{MPa}$ due to fine grain structure and high tungsten content while showed low elongation below $1 \%$ due to a low volume fraction of matrix phase and a large tungsten/tungsten contiguity.

(2) Finer spherical tungsten grains less than $7 \mu \mathrm{m}$ can be obtained by two-stage sintering of mechanically alloyed $94 \mathrm{~W}-4.56 \mathrm{Ni}-1.14 \mathrm{Fe}-0.3 \mathrm{Y}_{2} \mathrm{O}_{3}$ alloys with high relative density above $99 \%$. Two-stage sintered ODS tungsten heavy alloys showed finer tungsten grain size and higher tensile strength compared to the conventional liquid phase sintered ODS tungsten heavy alloy. 
(3) Yield strength of ODS tungsten heavy alloy was found to be dependent on the microstructural parameters such as tungsten grain size, matrix volume fraction and tungsten/tungsten contiguity, which can be controlled by the two-stage sintering process.

\section{Acknowledgement}

This work was supported from AOARD and AFOSR through the contract No. 034032.

\section{References}

[1] R.M. German, K.S. Churn, Metall. Trans. A 15 (1984) 747.

[2] E. Ariel, J. Barta, P. Brandon, Powder Metall. Int. 5 (1973) 126.

[3] J.W. Noh, E.P. Kim, H.S. Hong, W.H. Baek, K.S. Churn, S.J.L. Kang, Metall. Trans. A 24 (1993) 2411.

[4] M. Zhou, R.J. Clifton, J. Appl. Mech. 64 (1997) 487.

[5] D.K. Kim, S. Lee, H.S. Song, Met. Mater. Trans. A 29 (1998) 1057.

[6] E.P. Kim, M.H. Hong, W.H. Baek, I.H. Moon, Met. Mater. Trans. A 30 (1999) 627.
[7] D.K. Kim, S. Lee, H.J. Ryu, S.H. Hong, J.W. Noh, Met. Mater. Trans. A $31(2000) 2475$.

[8] A. Bose, G. Jerman, R.M. German, Powder Met. Int. 21 (1989) 9.

[9] J.H. Huang, G.A. Zhou, C.Q. Zhu, S.Q. Zhang, H.Y. Lai, Mater. Lett. 23 (1995) 47.

[10] G.R. Goren-Muginstein, A. Rosen, Mater. Sci. Eng. A 238 (1997) 351.

[11] H.J. Ryu, S.H. Hong, S. Lee, W.H. Baek, Met. Mater. 5 (2) (1999) 185.

[12] H.J. Ryu, S.H. Hong, W.H. Baek, Mater. Sci. Eng. A 291 (2000) 91.

[13] H.J. Ryu, S.H. Hong, W.H. Baek, J. Mater. Process. Technol. 63 (1997) 292.

[14] S.H. Hong, H.J. Ryu, W.H. Baek, Mater. Sci. Eng. A 333 (2002) 187.

[15] S.H. Hong, H.J. Ryu, Mater. Sci. Eng. A 344 (2003) 253.

[16] S.H. Park, D.K. Kim, S.H. Lee, H.J. Ryu, S.H. Hong, Metall. Mater. Trans. A 23 (2001) 2011.

[17] H.J. Ryu, S.H. Hong, Mater. Sci. Eng. A 363 (2003) 179.

[18] I.M. Lifshitz, V.V. Slyozov, J. Phys. Chem. Solids 19 (1961) 35.

[19] C. Wagner, Z. Electrochem. 65 (1961) 581.

[20] M.F. Ashby, Philos. Mag. 18 (1970) 399.

[21] L.S. Magnes, T.G. Farrand, Proceedings 1990 Army Science Conference, 1990, p. 149.

[22] A. Bose, R.M. German, Metall. Trans. A 19 (1988) 2467. 